\title{
Fine tuning in neuraxial subarachnoid anesthesia
}

\author{
Ovidiu PENES ${ }^{1}$, Emilia VALEANU ${ }^{2}$ \\ ${ }^{1}$ Department of Anesthesiology Intensive Care (ATI I) Clinical University Hospital, \\ "Carol Davila" University of Medicine and Pharmacy, Bucharest \\ ${ }^{2}$ Intern resident
}

\begin{abstract}
The spinal anesthesia, a category of neuraxial anesthesia, is commenced in the lumbar spine, where the local anesthetic (LA) is injected into cerebrospinal fluid (CSF) to anesthetize the spinal nerves. This technique is most frequently used for analgesia and/or anesthesia for different forms of lower extremity, lower abdominal, pelvic, and perineal procedures. Preoperative evaluation that includes a medical history and anesthesia-directed physical examination should be performed for every patient who undergo any type of anesthesia. Focus should be made on the preoperative evaluation, when spinal anesthesia is considered, to prevent medical conditions that may alter the physiologic response to spinal anesthesia or increase the risk of complications and the baricity influences of the anesthetic distribution within the subarachnoid space.
\end{abstract}

Keywords: spinal anesthesia, neuraxial anesthesia, cerebrospinal fluid (CSF), local anesthetic (LA)

\section{INTRODUCTION}

When the surgical area is located on the lower extremities, perineum, or lower body wall, a generally safe and effective alternative for general anesthesia (GA) is the subarachnoid (spinal) block. Spinal anesthesia has supplementary advantages compared to GA, for example: avoidance of airway management that accompanies general anesthesia and contribution in good operating conditions for the surgeon (1). Also normal gastrointestinal function returns faster and incidence of deep vein thrombosis and pulmonary emboli formation is decreased with spinal anesthesia, compared to general anesthesia (2).

Additional benefits may include reducing the metabolic stress response to surgery, blood loss reduction and patient's mental status monitoring.

Strong contraindications include patient refusal, lack of patient cooperation, difficulties with positioning, increased intracranial pressure, hypovolemia, coagulation disturbances, stenotic valvular disease, bacteremia, and infection at the site of needle insertion.

Spinal anesthesia has also been noted to result in symptomatic deterioration on patients with multiple sclerosis. Patients with chronic low back pain may decline spinal anesthesia out of concerns for increased low back pain. Performing spinal anesthesia on patients with degenerative lumbar spine disease or a prior history of lumbar surgery may become technically difficult, but these are not major contraindications.

Allergy to local anesthetics may also be a contraindication, but true allergies are usually found with ester-based local anesthetics, so is easy to find a suitable local anesthetic.

As the anterior and posterior nerve roots pass through the CSF, sensory, autonomic, and

\section{Corresponding author:}

Ovidiu Penes, “Carol Davila” University of Medicine and Pharmacy, 37 Dionisie Lupu Street, Bucharest

E-mail: office@drovidiupenes.ro 
motor impulses are blocked by the local anesthetics, administered in the subarachnoid space. The site of action includes the spinal nerve roots and dorsal root ganglion (3).

In the adult patient's case the anesthesia provider places the needle below L2 vertebra, to avoid trauma to the spinal cord. Light sedation may be administered if necessary prior to needle placement in the spinal region, whereas deep sedation should be avoided in order to allow patient cooperation with positioning and feedback. Optimal patient positioning is critical to the success of neuraxial procedures. The goals of positioning are to avoid rotation of the spine and to create a straight path for needle insertion between the vertebrae.

\section{Lateral decubitus position}

Either side, the lateral decubitus position can be used and may be chosen based on the baricity of the spinal drug preparation. As an example, the patient should be positioned with the left side down, if hyperbaric medication is used for a left leg procedure. On condition that baricity relative to surgical position is not a concern, the left lateral position is usually more comfortable for a right-handed clinician.

\section{Sitting position}

The sitting position may be particularly useful for larger patients in whom the bony landmarks are difficult to feel. If the patient sits straight, the midline may be easier to estimate, compared with the lateral position. In this posi- tion, the patient's legs should hang off the side of the bed, with the feet planted on a fix stool. The posterior wall of the knees should be against the edge of the bed so that the patient's back is as close as possible to the clinician standing on the other side of the bed. To allow flexion of the lumbar spine, the patient is asked to "slouch" symmetrically with shoulders over the hips. We usually have the patient sit with the arms bent at the elbows, with forearms and hands resting lightly on the thighs. Alternatively, the patient can rest the arms on a padded Mayo stand. In order to prevent the increase of the lumbar lordosis, the patient should not lean forward. In addition, positioning aids, designed to support the patient in the sitting position during neuraxial block (Fig. 1), are available.

\section{Prone position}

This position is sometimes used for spinal anesthesia in rectal or pilonidal surgery. The patient is positioned on chest supports, with the hips flexed (i.e., the jackknife position). In this setting, hypobaric or isobaric spinal medication is used to primarily anesthetize low lumbar and sacral nerve roots.

\section{EQUIPMENT}

- Sterile drapes;

- Spinal kit with thin needle and introducer;

- Local anesthetics (to anesthetize the skin and soft tissues that the spinal needle will pass through);
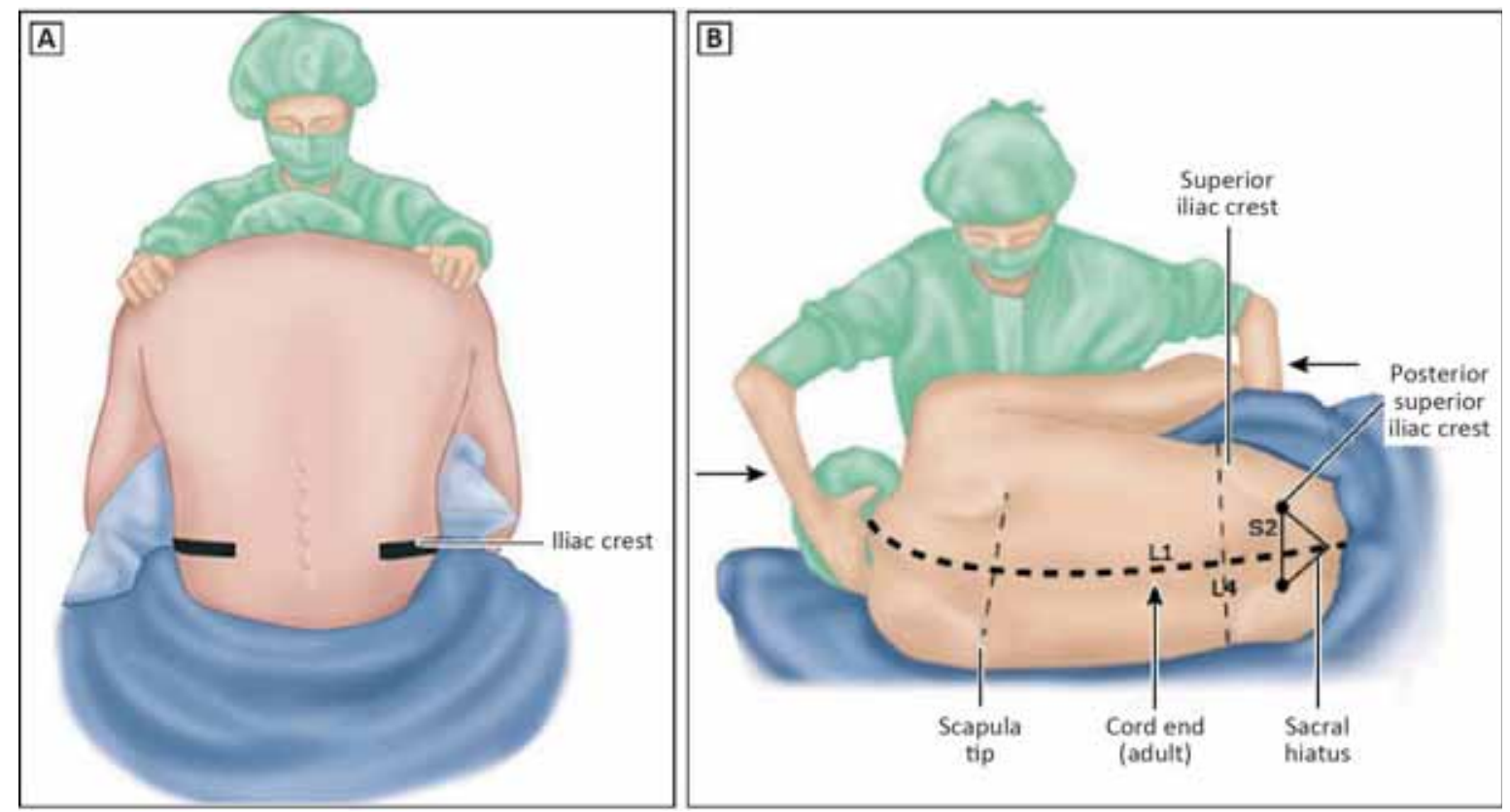
- A hyperbaric solution of bupivacaine hydrochloride;

- Facial mask to administer oxygen;

- Emergency kit.

\section{TECHNIQUE}

After a 20-gauge IV cannula had been inserted at the forearm and standard volume infusion of lactated Ringer's solution was given, the patient is premedicated with midazolam. It is positioned in lateral decubitus. A useful landmark, that coincides with the L3-L4 interspace, is the line from the top of both iliac crests. Either, a midline or paramedian approach can be used. The patient is asked to curl his or her back dorsally, opening up the intervertebral spaces. The goal is to inject the chosen medication(s) into the cerebrospinal fluid-filled subarachnoid space. To achieve this, the thin needle will pass through skin, subcutaneous tissue, supraspinous ligament, interspinous ligament, ligamentum flavum, epidural space, dura mater, and subarachnoid membrane. The correct space is identified by return of cerebrospinal fluid through the spinal needle (4). Clear cerebrospinal fluid drips out of the spinal needle, confirming the correct posi- tion within the subarachnoid space. It's slowly injected the anesthetic substance to achieve a high concentration on a limited area (5).

For the normal weight people we injected $7.5 \mathrm{mg}$ hyperbaric bupivacaine hydrohloride. The patient remains on the side of surgery for 10 minutes (6). In order to maintain preferential anesthetic distribution to the dependent side, it is recommended to keep the patient in the lateral decubitus position for 10 min after hyperbaric bupivacaine hydrochloride spinal anesthesia (7).

The hemodynamic changes are minimal, it is not necessary to administer a vasopressor, respiratory distress absence, there were not adverse reactions like nausea, vomiting and/or headache.

In conclusion, patient's position, during blockade, is one of the most important factors along with local anesthetic and baricity that can affect the spread of local anesthetic and subsequent block height.

We have noticed in the context of maintaining quality anesthesia, that, by lowering the required dosage of anesthetic and maintaining lateral decubitus of patient during/immediately after injection, very slow, with little pressure in-

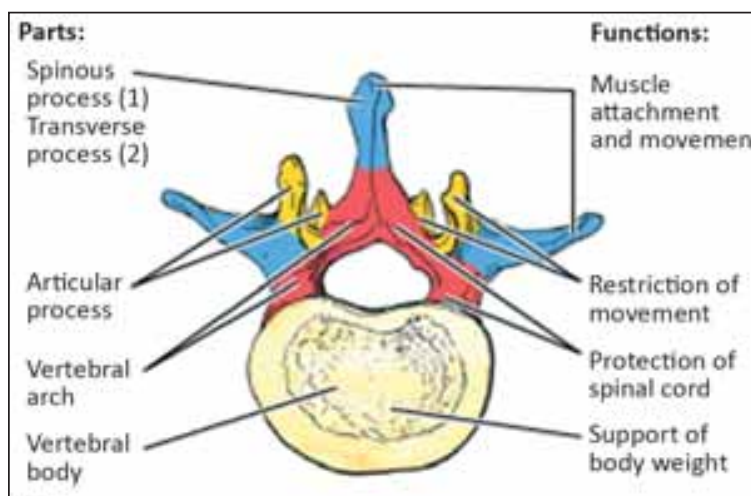

A

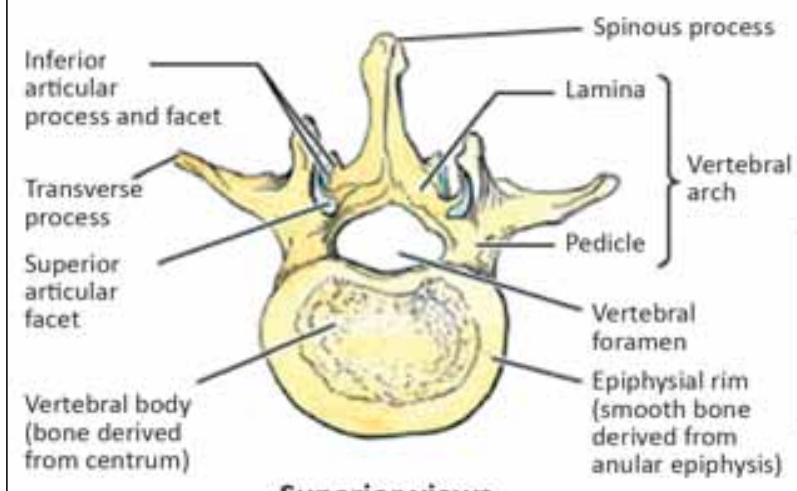

B
Superior views

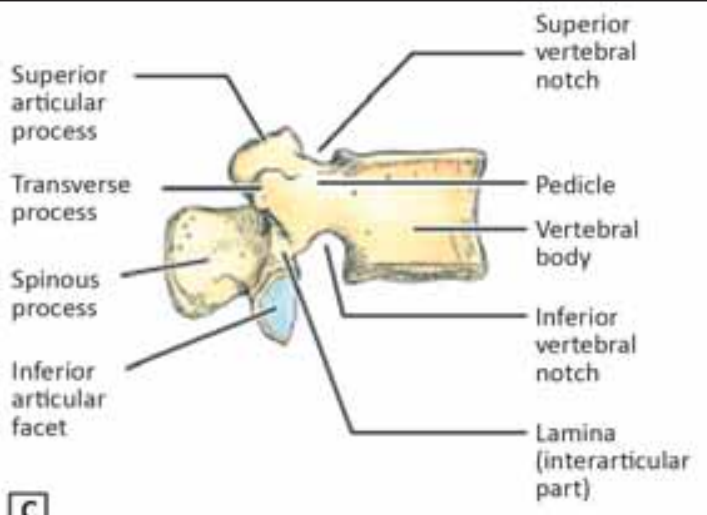

C

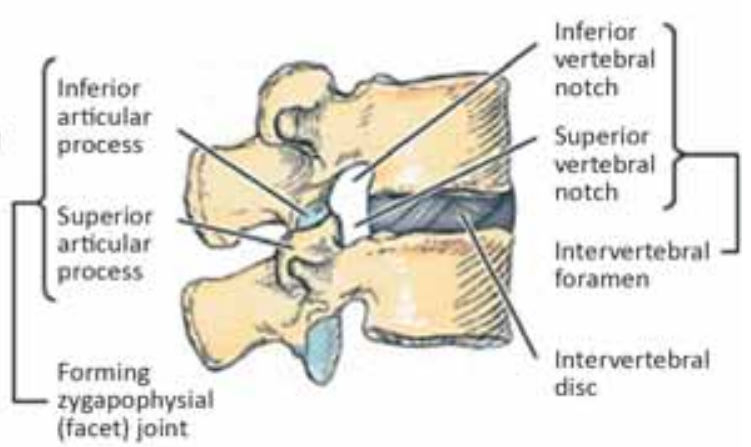

Lateral views 


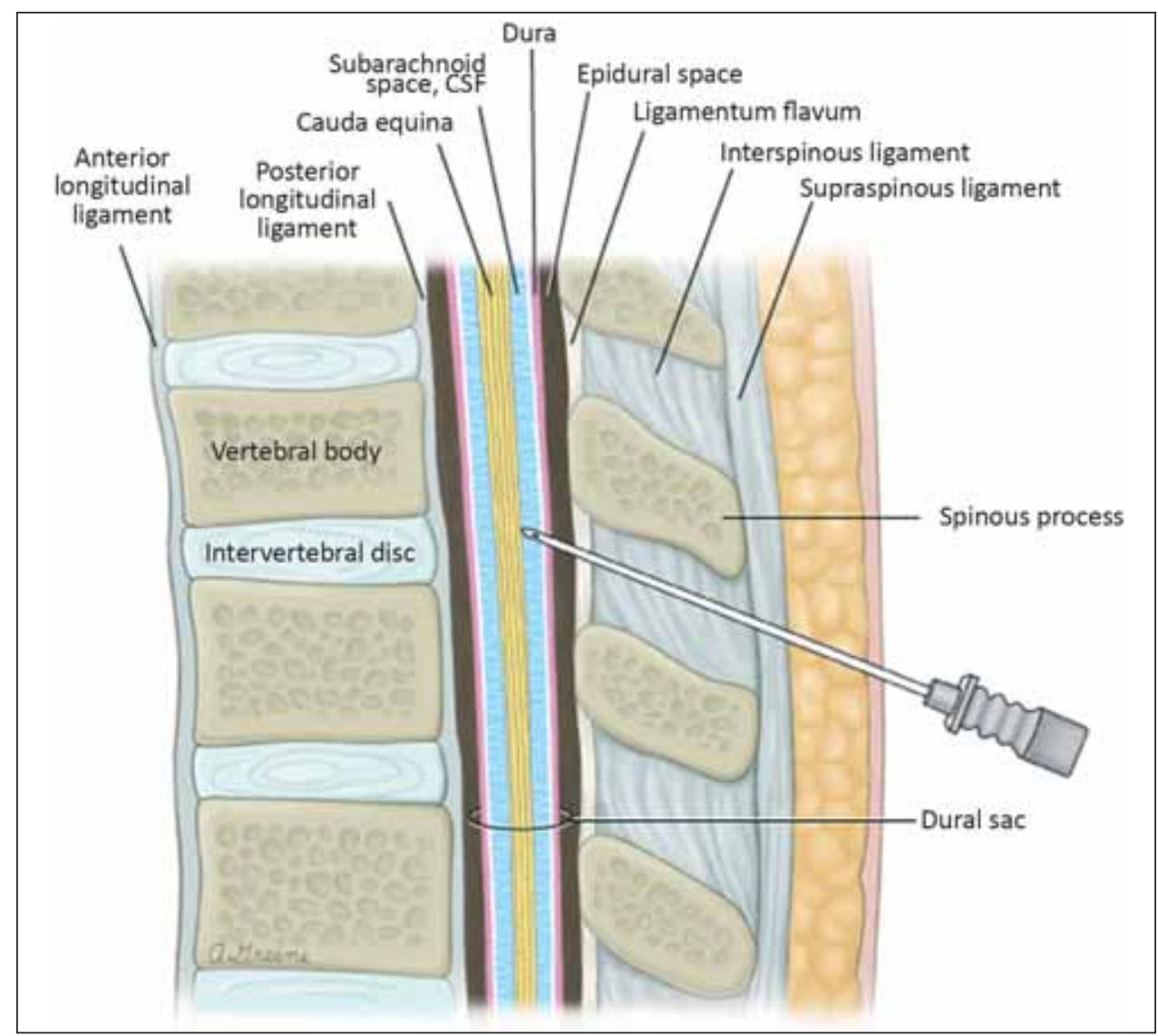

jection, will substantially decrease the possibility of adverse reactions (8).

\section{POST-INJECTION POSITIONING}

The timing and characteristics of patient positioning, after anesthetic injection, depend on the required level of block, the baricity of the spinal solution, and the position used for the spinal injection.

\section{HYPERBARIC SPINAL SOLUTIONS}

If a hyperbaric solution is injected for a perineal surgical procedure, the patient shouldachieve, what is called, a "saddle block", by sitting for several minutes, to allow the anesthetic solution to sink to the sacral nerve roots (9). In contrast, if a high thoracic spinal level is required, the patient should be placed in the supine position immediately after injection. The tilt of the operating table should be adjusted based on the level of the block.

\section{ISOBARIC OR HYPOBARIC DRUG}

If a plain (slightly hypobaric) solution is injected in the sitting position, or in the lateral position for bilateral surgery, the patient should be placed supine immediately after injection. If a plain solution is injected in the lateral position for surgery on the nondependent side (eg, hip replacement), the patient should remain in the lateral position and prepared for intervention (10).

\section{CHOICE OF SPINAL DRUGS}

LAs and adjuvant medications must be chosen to achieve the required spinal level and duration for single-shot spinal anesthesia. The dose and baricity (relative to the patient's position) of the anesthetic solution are the most important determinants of the extent of sensory block. Less important variables include patient age, body mass index, orientation of the pencilpoint spinal needle orifice, and the angle of the needle relative to the neuraxis.

\section{BARICITY}

Baricity refers to the density of a substance, compared to the density of cerebrospinal fluid (CSF). Solutions with the same density as CSF are called isobaric and have a baricity of 1 . Solutions more dense than CSF are called hyperbaric and 
those less dense than CSF are called hypobaric. The baricity of local anesthetic (LA) should be known. Baricity influences the distribution of anesthetic solution within the subarachnoid space. For example, hyperbaric solutions tend to "sink" within the CSF relative to the site of injection and hypobaric solutions rise relative to the site of injection, while gravity has no effect on the distribution of isobaric solutions in CSF. The patient's position during and after injection of spinal drugs influences the extent of spinal block with hyperbaric or hypobaric drugs (11).

To increase the density and duration of spinal block at the site of surgery, the baricity of the anesthetic solution, along with the patient's position are used. As an example, a saddle block (i.e., low lumbar and sacral nerve block) can be achieved by injecting a hyperbaric solution in the sitting position and keeping the patient sitting for several minutes. Conversely, spinal anesthesia for rectal surgery can be performed with a hypobaric solution injected with the patient in a jackknife position.

Recently, a great study of thought was made regarding the rate of injection (12). A prospective, randomized, double-blind study was performed to investigate whether altering the rate of injection of local anaesthetic through a Whitacre needle had any effect on the spinal block. The level of peak sensory block was similar: T3.5 (T2-T4.5) vs T4 (T1.5-T6.5). The time to lowest mean arterial pressure occurred earlier in the slow group, at 10 (8 to 18) vs 20 (15-31) $\min (P<0.05)$. Duration of the motor block was shorter in the slow group: 180 (152-242) vs 270 (225-300). We conclude that a slow spinal injection of plain bupivacaine results in a block of more rapid onset and recovery.

\section{REFERENCES}

1. Lim Y.C., Choo C.Y., Tan K.T. A randomised controlled trial of ultrasoundassisted spinal anaesthesia. Anaesth Intensive Care 2014; 42:191.

2. Greene N.M.- Distribution of local anesthetic solutions within the subarachnoid space. Anesth Analg 1985; 64:715.

3. Hejtmanek M.R., Pollock J.E. Chloroprocaine for spinal anesthesia: a retrospective analysis. Acta Anaesthesiol Scand 2011; 55:267.

4. Broadbent C.R., Maxwell W.B., Ferrie R., et al. Ability of anaesthetists to identify a marked lumbar interspace. Anaesthesia 2000; 55:1122.

5. Tsen L.C., Hepner D.L. Needles used for spinal anesthesia. Expert Rev Med Devices 2006; 3:499.
6. McDonald S.B., Liu S.S., Kopacz D.J., Stephenson C.A. Hyperbaric spinal ropivacaine: a comparison to bupivacaine in volunteers. Anesthesiology 1999; 90:971.

7. Davis H., King W.R. Densities of cerebrospinal fluid of human beings. Anesthesiology 1954; 15:666.

8. Ovidiu Penes et al. Studiu comparativ asupra calității şi duratei anesteziei neuroaxiale subdurale hiperbare în funcție de viteza de administrare şi decubit, Jurnalul Societății Române de Anestezie şi Terapie Intensivă, ISSN 1582-652X, 2006.

9. Kuusniemi Kristiina S., Pihlajamäki Kalevi K., Pitkänen Mikko T. A Low Dose of Plain or Hyperbaric Bupivacaine for Unilateral Spinal Anesthesia. Regional Anesthesia \& Pain Medicine: November/ December 2000, Volume 25.
10. Khaw K.S., Ngan Kee W.D., Wong M., et al. Spinal ropivacaine for cesarean delivery: a comparison of hyperbaric and plain solutions. Anesth Analg 2002; 94:680.

11. Chambers W.A., Edstrom H.H., Scott D.B. Effect of baricity on spinal anaesthesia with bupivacaine. Br J Anaesth 1981; 53:279.

12. Anderson L., Walker J., Brydon C., Serpell M.G. Rate of injection through Whitacre needles affects distribution of spinal anaesthesia, Oxford Journals Medicine \& Health BJA, Volume 86, Issue 2, Pp. 245-248. 